\title{
Successful endoscopic lithotripsy using a new digital cholangioscope through an overtube placed by an enteroscope
}

A 29-year-old woman who had undergone extrahepatic bile duct resection and hepaticojejunostomy for congenital biliary dilation was admitted to our hospital with cholangitis. Magnetic resonance cholangiopancreatography revealed multiple large intrahepatic bile duct stones ( $\triangleright$ Fig. 1 ). Most of the stones were fragmented and removed by extracorporeal shock wave lithotripsy and endoscopic mechanical lithotripsy (LithoCrush V; Olympus, Tokyo, Japan) during double-balloon endoscope-assisted endoscopic retrograde cholangiopancreatography (El-580BT; Fujifilm, Tokyo, Japan). However, intrahepatic stones in the right posterior branch could not be removed owing to the acute angle of the duct ( $\triangleright$ Fig. 2). To perform intraductal lithotripsy under direct visualization, the enteroscope was withdrawn while leaving the overtube in situ. The direct cholangioscope (SpyGlass DS Direct Visualization System; Boston Scientific Japan, Tokyo, Japan) was successfully advanced through the overtube into the right posterior branch. The intrahepatic stones were visualized ( $\triangleright$ Fig. $\mathbf{3}$ ) and successfully fragmented by electrohydraulic lithotripsy using the Autolith EHL system and 1.9-Fr probe (Boston Scientific Japan). Finally, the cholangioscope was exchanged for the enteroscope, and fragmented stones were extracted using a balloon catheter ( $>$ Fig. 4, > Video 1 ). Endoscopic removal of large bile duct stones remains challenging, especially in cases with surgically altered anatomy [1, 2]. Direct insertion of an enteroscope is possible in cases with a large bile duct [3-5], though this technique cannot be utilized in cases with intrahepatic stones in small bile ducts. To our knowledge, this is the first report of successful endoscopic treatment of intrahepatic bile duct stones under direct cholangioscopy in a patient with surgically altered anatomy. Although scope exchange to a direct cholangioscope through the overtube is

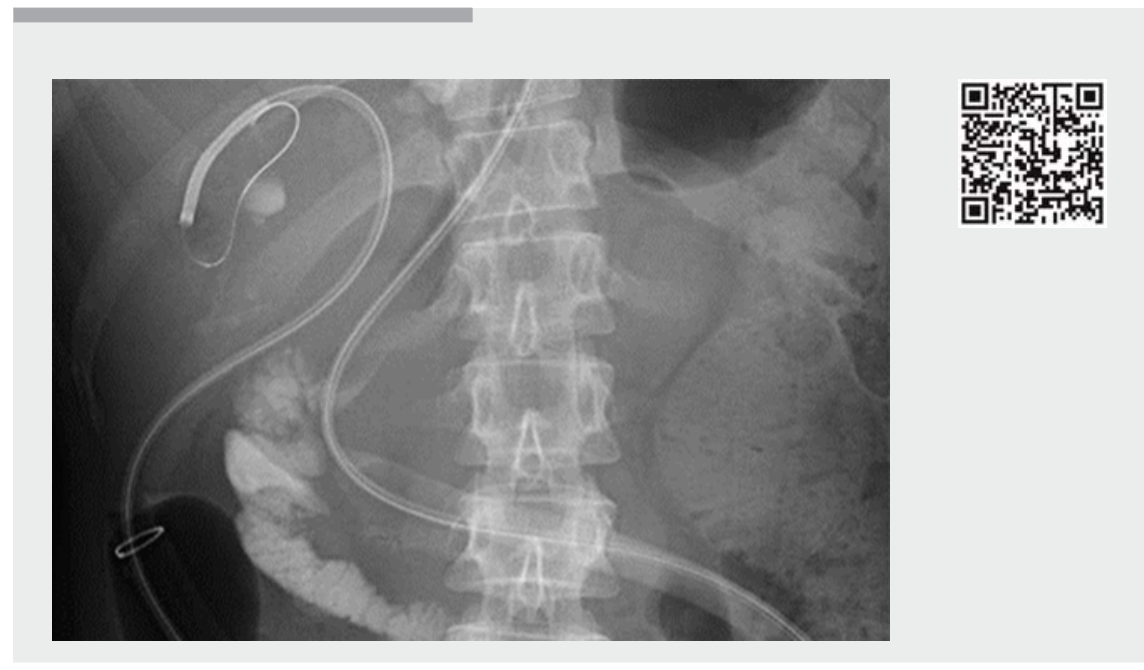

Video 1 The cholangioscope was successfully advanced into the right posterior branch through the overtube. The intrahepatic bile duct stones were fragmented using electrohydraulic lithotripsy under direct visualization.

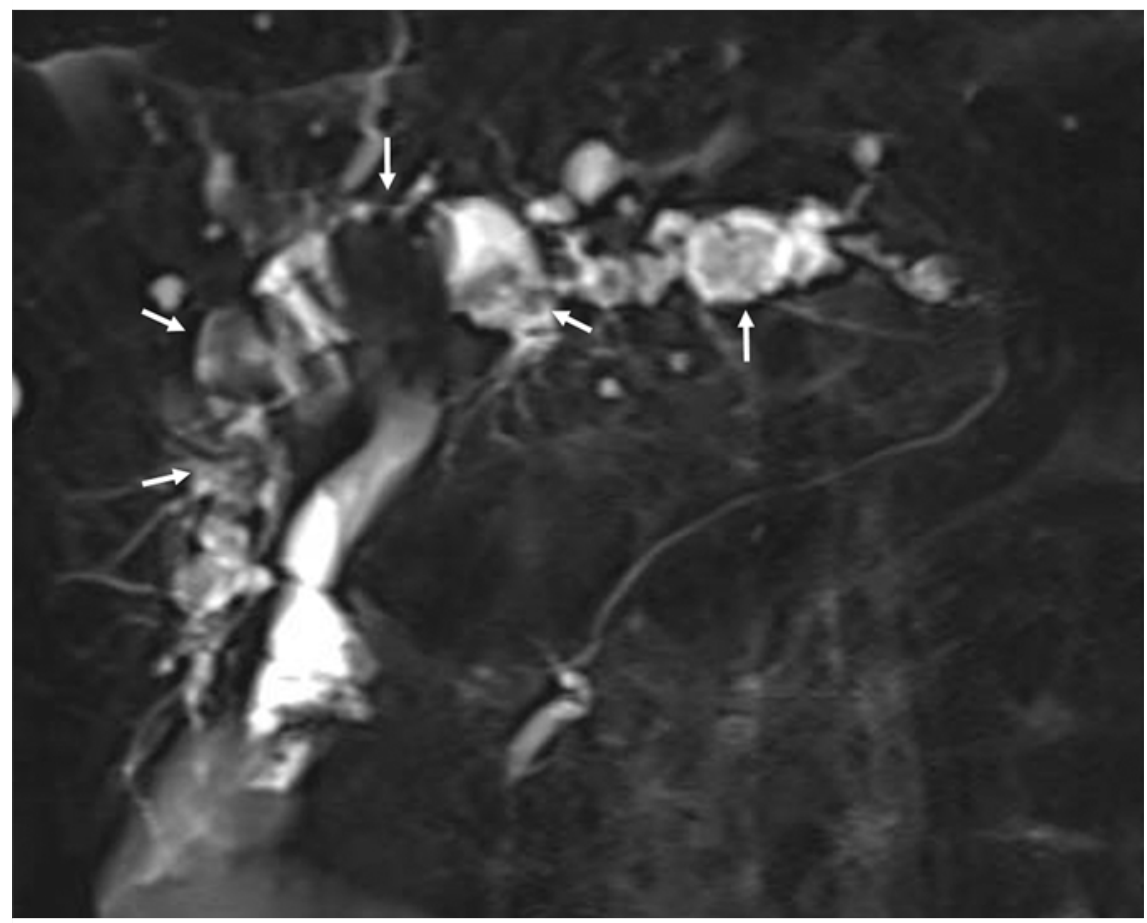

- Fig. 1 Magnetic resonance cholangiopancreatography revealed multiple large intrahepatic bile duct stones (arrows). 


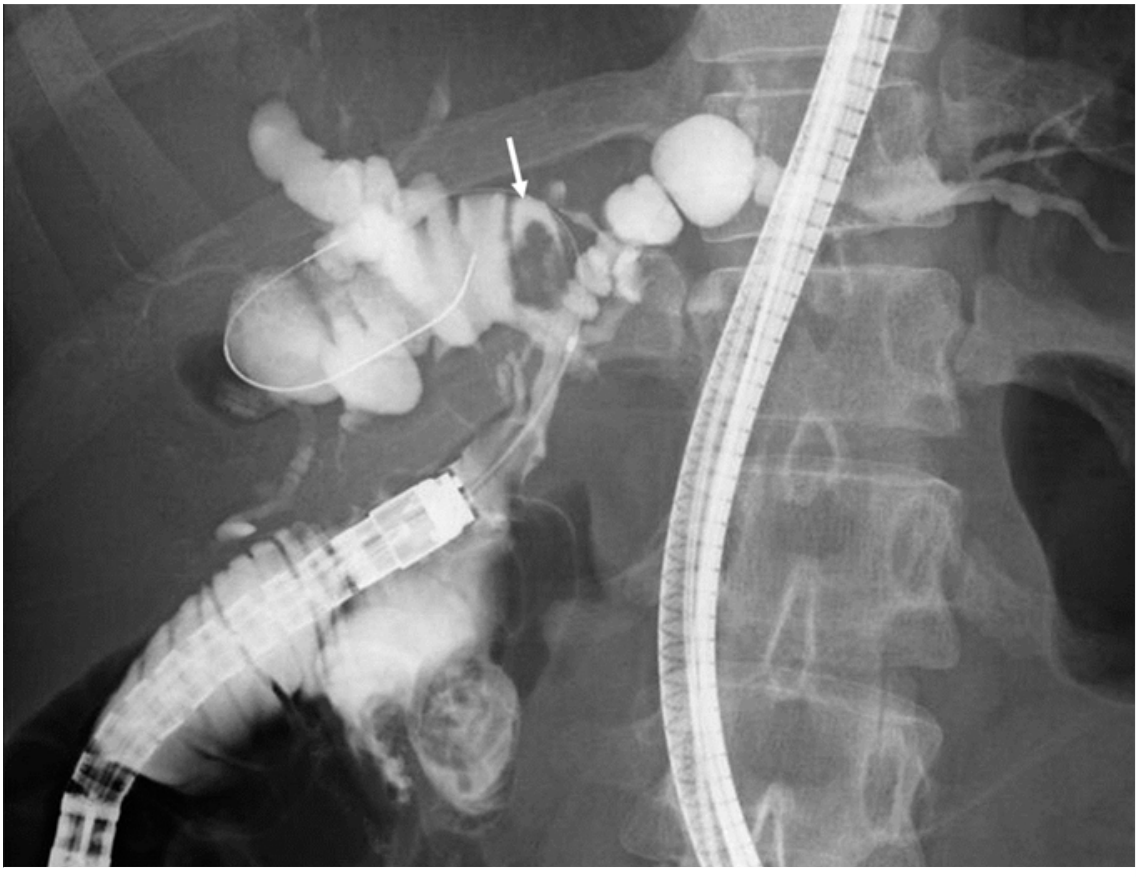

- Fig. 2 Endoscopic mechanical lithotripsy and extracorporeal shock wave lithotripsy fragmented the stones. Intrahepatic bile duct stones in the right posterior branch (arrow) could not be removed due to the acute angle of the duct.
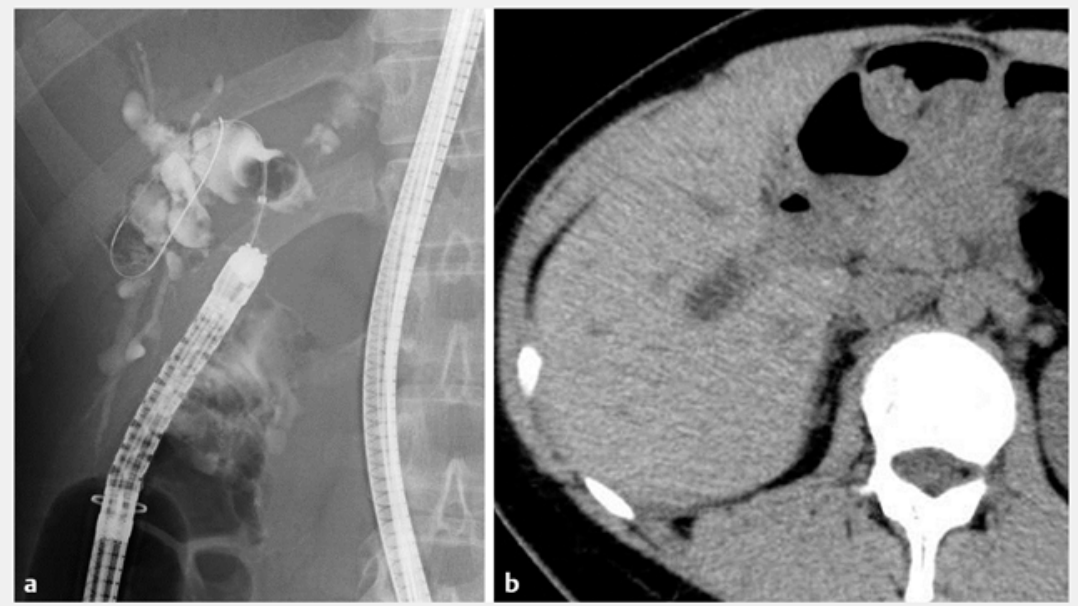

- Fig. 4 Complete stone removal in the right posterior branch was confirmed by cholangiogram using a balloon catheter (a) and computed tomography (b).

technically possible only when the overtube is completely straight, without any loops, as in our case ( $\triangleright$ Fig. $\mathbf{5}$ ), this new method is an additional option for the management of intrahepatic bile duct stones after hepaticojejunostomy.

Endoscopy_UCTN_Code_TTT_1AR_2AH

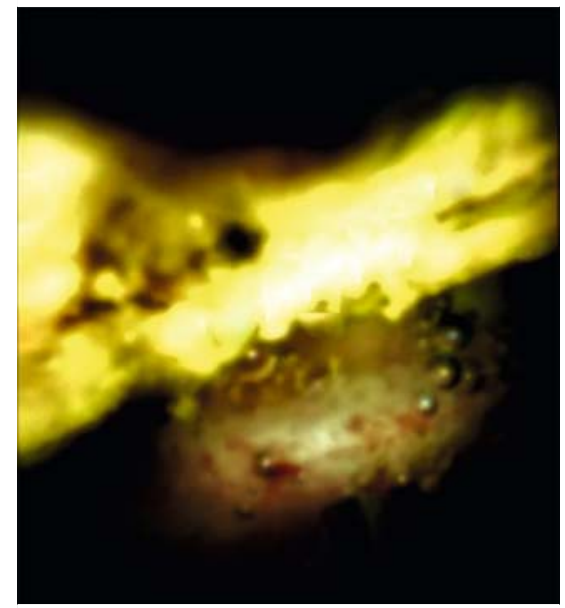

- Fig. 3 Cholangioscopic view of bile duct stone in the right posterior branch.

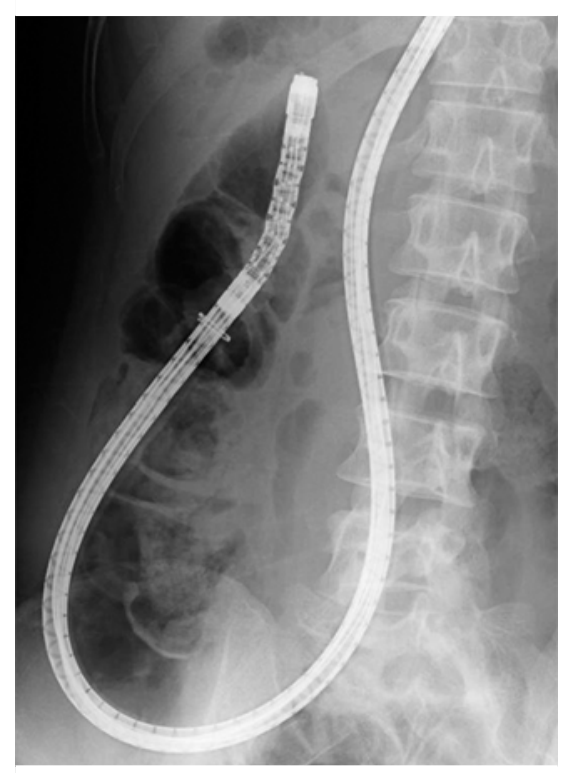

- Fig. 5 The enteroscope and overtube were completely straight without any loops.
The authors

\section{Ryunosuke Hakuta, Hirofumi Kogure,} Yousuke Nakai, Atsuo Yamada, Naminatsu Takahara, Suguru Mizuno, Kazuhiko Koike Department of Gastroenterology, Graduate School of Medicine, University of Tokyo, Tokyo, Japan 
Corresponding author

\section{Yousuke Nakai, MD, PhD}

Department of Gastroenterology, Graduate School of Medicine, The University of Tokyo, 7-3-1 Hongo Bunkyo-ku, Tokyo, Japan 1138655

Fax: +81-3-5800-9801

ynakai-tky@umin.ac.jp

\section{References}

[1] Oana S, Shibata S, Matsuda $N$ et al. Efficacy and safety of double-balloon endoscopyassisted endoscopic papillary large-balloon dilatation for common bile duct stone removal. Dig Liver Dis 2015; 47: 401 - 404

[2] Shimatani M, Takaoka M, Okazaki K. Tips for endoscopic stone extraction using new short-type double balloon endoscope for common bile duct stones in patients with surgically altered gastrointestinal anatomy. Dig Endosc 2018; 30: 130-131

[3] Hakuta R, Kogure H, Isayama $\mathrm{H}$ et al. Electrohydraulic lithotripsy as a salvage option for stone impaction during double-balloon endoscope-assisted ERCP. Gastrointest Endosc 2016; 84: 177

[4] Hakuta R, Kogure H, Isayama $\mathrm{H}$ et al. Electrohydraulic lithotripsy of large bile duct stones under direct cholangioscopy with a double-balloon endoscope. Endoscopy 2015; 47 (Suppl. 01): E519-E520

[5] Yamauchi H, Kida M, Miyazawa S et al. Electrohydraulic lithotripsy under peroral direct cholangioscopy using short-type single-balloon enteroscopy for large common bile duct stone in patients with Roux-en-Y gastrectomy. Endoscopy 2015; 47 (Suppl. 01): E240 - E241

\section{Bibliography}

DOI https://doi.org/10.1055/a-0640-2817

Published online: 3.7.2018

Endoscopy 2018; 50: E269-E271

(c) Georg Thieme Verlag KG

Stuttgart · New York

ISSN 0013-726X

\section{ENDOSCOPY E-VIDEOS}

https://eref.thieme.de/e-videos

回回 Endoscopy E-Videos is a free ty access online section, reportin 回和量: on interesting cases and new

techniques in gastroenterological endoscopy. All papers include a high quality video and all contributions are freely accessible online.

This section has its own submission website at https://mc.manuscriptcentral.com/e-videos 